\title{
The Effects of Nerve Growth Factor on Spatial Recent Memory in Aged Rats Persist after Discontinuation of Treatment
}

\author{
Karyn M. Frick, ${ }^{1}$ Donald L. Price, ${ }^{2}$ Vassilis E. Koliatsos, ${ }^{2}$ and Alicja L. Markowska ${ }^{1}$ \\ ${ }^{1}$ Department of Psychology, The Johns Hopkins University, Baltimore, Maryland 21218, and 2Departments of Pathology, \\ Neurology, and Neuroscience, The Johns Hopkins University School of Medicine, Baltimore, Maryland 21205
}

\begin{abstract}
Nerve growth factor (NGF) infusion significantly reduces spatial recent memory deficits in aged rats, an effect that has great relevance to the treatment of memory impairments characteristic of patients with Alzheimer's disease. The present study was designed to examine whether this NGF-induced improvement in spatial recent memory persists after the discontinuation of NGF treatment, an issue of crucial importance for the potential clinical use of this compound. Spatial recent memory was tested in a Morris water maze delayed nonmatch-to-position task. In addition to memory, sensorimotor skills were also examined. Four- and 22-month-old rats were tested preoperatively, infused intraventricularly with recombinant human NGF or vehicle, and tested both during the 4 week infusion period and during the 4 weeks after discontinuation of the infusion.
\end{abstract}

NGF significantly improved spatial recent memory in 22-monthold rats only, during the 4th week of infusion and for up to 4 weeks after discontinuation of the infusion. Although NGF did not affect overall sensorimotor skills during infusion in either age group, sensorimotor skills were significantly improved both 2 and 4 weeks after discontinuation of infusion in 22-month-old rats. These findings demonstrate that the beneficial effects of NGF on spatial recent memory can persist for up to 1 month after discontinuation of infusion and suggest that NGF can be used intermittently for the treatment of age-associated memory dysfunction and Alzheimer's disease.

Key words: neurotrophins; aging; water maze; delayed nonmatch-to-position; working memory; body weight
Deficits in recent memory are characteristic of normal human aging and Alzheimer's disease (AD; Craik, 1977; Bondi et al., 1994). These age-associated deficits are strikingly similar to those observed in humans, nonhuman primates, and rodents with damage to the basal forebrain and hippocampus (Scoville and Milner, 1957; Olton, 1977; Damasio et al., 1985; Squire et al., 1988). Because of the extensive cholinergic projections from the septal area of the basal forebrain to the hippocampus (Mesulam et al., 1983; Rye et al., 1984; Frotscher and Leranth, 1985; Koliatsos et al., 1990a) and the documented adverse effects of anticholinergic agents on recent memory (Drachman and Leavitt, 1974), basal forebrain cholinergic neurons have been hypothesized to be critical for certain types of memory (Bartus et al., 1985). Evidence that reductions in basal forebrain cholinergic function occur early and correlate significantly with the magnitude of cognitive impairments in patients with AD (Francis et al., 1994) implicates this neuronal population in age-associated memory decline and provides a target for pharmacological treatment of memory loss.

Because simple synaptic interventions to stimulate remaining cholinergic neurons in Alzheimer's brains have met with limited success (Thal, 1994), treatments with compounds such as trophic factors, which promote the growth and survival of specific neuro-

Received Sept. 27, 1996; revised Dec. 5, 1996; accepted Dec. 11, 1996.

This study was supported by Program Project Grant P5020417. V.E.K. and D.L.P. were the recipients of the Leadership and Excellence in Alzheimer's Disease Award (NIA AG 07914) and a Javits Neuroscience Investigator Award (National Institutes of Health Grant NS 10580). We thank Dr. L. E. Burton and Genentech (South San Francisco, CA) for their generous supply of recombinant human NGF, Dr. R. R. Sukhov for assistance with surgery, K. LeBlanc, S. Knight, L. Hendricks, and T. Coffey for assistance with behavioral testing, S. Sipes for statistical assistance, and Dr. G. Ball for comments on this manuscript.

Correspondence should be addressed to Dr. Alicja L. Markowska, Department of Psychology, The Johns Hopkins University, Baltimore, MD 21218.

Copyright (C) 1997 Society for Neuroscience $\quad 0270-6474 / 97 / 172543-08 \$ 05.00 / 0$ nal populations, recently have become promising alternatives. Of the known members of the neurotrophin growth factor family, nerve growth factor (NGF) exerts the most potent effects on basal forebrain cholinergic neurons (Koliatsos et al., 1994). NGF administered into the lateral ventricles ameliorates lesion-induced degeneration of basal forebrain cholinergic neurons in rats and primates (Hefti, 1986; Williams et al., 1986; Koliatsos et al., 1990b, 1991a; Tuszynski et al., 1990) and increases the size and transmitter synthesis of these cells in aged rats (Fischer et al., 1987; Rylett et al., 1993). As with aged humans, aged rats show significant impairments in recent (working) memory (deToledoMorrell et al., 1984; Markowska et al., 1994, 1995), a deficiency that correlates with dysfunction of basal forebrain cholinergic neurons (Luine and Hearns, 1990). NGF infusion in aged rats ameliorates deficits in both spatial recent and reference memory (Fischer et al., 1987, 1994; Markowska et al., 1994, 1996), although the effects on spatial recent memory appear to be more robust (Markowska et al., 1994, 1996).

Despite the fact that NGF-induced improvements in spatial memory are well documented, the duration of these improvements after discontinuation of NGF infusion is unknown. For example, NGF induces structural changes in the cell bodies of cholinergic neurons and, possibly, in the processes of postsynaptic neurons in the cerebral cortex (Fischer et al., 1987; Mervis et al., 1991). Therefore, it is likely that at least part of the effects of NGF on spatial memory are mediated via lasting changes in neuronal structure. However, published studies on the effects of NGF in aged rats have tested memory only during NGF administration, and therefore, it is unknown whether NGF-induced improvements are transient or persistent. On the other hand, there is a growing appreciation of the role of NGF as a mediator of cutaneous hyperalgesia (Woolf et al., 1996), a phenomenon that has 


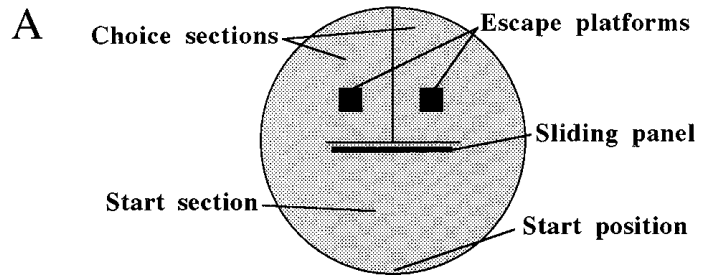

B

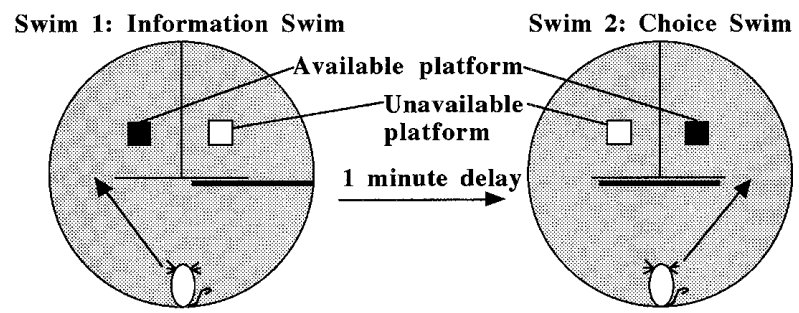

Figure 1. A, Schematic diagram representing the water tank apparatus (1.8 $\mathrm{m}$ in diameter) used in the DNMTP task (Markowska et al., 1996). One escape platform, submerged beneath the surface of the water, was placed in each choice section. Each platform could be made unavailable for escape by additional submersion to a greater depth. $B$, Schematic diagram illustrating the DNMTP procedure (Markowska et al., 1996). Two pretraining procedures were used: straight swim (1 session, 10 trials), which trained the rats to swim to a platform (Markowska et al., 1994), and shaping ( 2 sessions, 8 trials/session), which trained the rats to swim to the platforms located in either choice section (Markowska et al., 1996). Only one choice section was open during each shaping trial, and the starting point was at the entrance to an open choice section (session 1) or at the start position (session 2). See Materials and Methods for additional details on the DNMTP procedure.

been often encountered in subjects receiving NGF as part of ongoing clinical trials (Petty et al., 1996). Therefore, a decrease in the length or frequency of treatment with NGF, as might be expected to occur with intermittent delivery, could reduce the occurrence of unacceptable side effects.

This study was designed to determine whether NGF-induced improvements in the spatial recent memory of aged rats persist after the discontinuation of NGF treatment. Spatial recent memory was examined with a water maze delayed nonmatch-toposition (DNMTP) task (Markowska et al., 1996), conducted both during NGF infusion and for 1 month after the discontinuation of NGF. Sensorimotor skills during and after NGF infusion were also measured using a battery of sensorimotor tasks.

\section{MATERIALS AND METHODS}

Subjects. Male Fischer-344 rats, 4 and 22 months old at the time of surgery, were obtained from the NIA colony at Harlan Sprague Dawley (Indianapolis, IN). Rats were housed two to three per cage in a room with a 12:12 light/dark cycle, and behavioral testing was performed during the light phase of the cycle. Food and water were provided ad libitum. Body weight was monitored throughout the experiment. After preoperative testing, each rat was assigned to one of two treatment groups, vehicle control (VEH) or NGF, to create four experimental groups: 4-month-old vehicle-infused ( $4 \mathrm{moVEH}, n=6$ ), 4-month-old NGF-infused (4moNGF, $n=8)$, 22-month-old vehicle-infused (22moVEH, $n=8)$, and 22-monthold NGF-infused (22moNGF, $n=10$ ). Group assignments were made based on preoperative performance in the DNMTP task, such that the mean preoperative performance during the last three sessions was similar between the two treatment groups at each age.

DNMTP. Choice accuracy in the DNMTP task (Fig. 1) was used to measure spatial recent memory (Markowska et al., 1996). One session (9 trials/session, 10 min intertrial interval) was conducted each day. Each trial consisted of two swims: an information swim and a choice swim. For the information swim, one choice section was blocked, and the other choice section was left open. Rats were allowed $60 \mathrm{sec}$ to locate the platform in the open section. The interswim interval was 1 min. For the choice swim, both choice sections were open, but only the platform in the section that was previously closed (the correct section) was available for escape. When the rat entered the correct section, a correct response was recorded, and $60 \mathrm{sec}$ was allowed to locate the platform. If the rat entered the incorrect section, an incorrect response was recorded, and the sliding panel confined the rat in the incorrect section for $30 \mathrm{sec}$. After this period, the incorrect section was opened, and the rat was allowed to find the platform in the correct section. Choice accuracy and time to find the platform were recorded.

Sensorimotor tasks. Six sensorimotor tasks (1 trial/task/d) measured orientation, strength, balance, and coordination. These tasks have been described previously (Markowska et al., 1989, 1994; Ingram et al., 1994) and were as follows: time to turn in a wooden alley, time to fall or escape from a series of suspended wooden bridges (2- or 6-cm-wide flat bridges or 2-cm-diameter round bridge), time to fall from a suspended horizontal wire, and time to fall from a suspended inclined screen. A maximum of $120 \mathrm{sec}$ was allowed for the completion of each task except for the inclined screen, in which $30 \mathrm{~min}$ was allowed. Because two different times were recorded for each of the three bridge tasks (time to escape and time to fall), a total of nine sensorimotor measures were analyzed.

Surgery. Surgical procedures for osmotic minipump implantation have been described in detail previously (Koliatsos et al., 1991a; Markowska et al., 1994). Rats were anesthetized with a mixture of $\mathrm{O}_{2}, \mathrm{~N}_{2} \mathrm{O}_{2}$, and enflurane (Ohmeda, Liberty Corner, $\mathrm{NJ}$ ) and given chloramphenicol (15 $\mathrm{mg} / \mathrm{ml}$, i.p.) before and after surgery to prevent infection. Under aseptic conditions, a cannula (Alza Corporation, Palo Alto, CA) was placed into the right or left lateral ventricle at the following coordinates: $1.0 \mathrm{~mm}$ posterior to bregma, $1.5 \mathrm{~mm}$ on either side of the midline, and $4.5 \mathrm{~mm}$ ventral to dura. An Alzet 2002 osmotic minipump (Alza Corporation) filled with either recombinant human NGF (40 $\mu \mathrm{g} / \mathrm{pump}$; donated by Genentech, San Francisco, CA) or an artificial CSF vehicle (Koliatsos et al., 1990b) was connected to the cannula. After $14 \mathrm{~d}$, each pump was replaced with a new pump filled with an identical solution. At the completion of all behavioral testing, each rat was perfused transcardially with $0.1 \mathrm{M}$ PBS and $4 \%$ paraformaldehyde in $0.1 \mathrm{M}$ PBS. Brains were removed for histological verification of the cannula placement.

Experimental design. The schedule of behavioral testing and surgery is presented in Figure 2. Preoperative behavioral testing established baseline levels of performance for all animals. Postoperative testing took place twice during drug administration (weeks 1-4 in Fig. 2) and twice after discontinuation of NGF administration (weeks 5-8 in Fig. 2). Test periods were called POST1 (week 2 of infusion), POST2 (week 4 of infusion), POST3 (week 2 after discontinuation of infusion), and POST4 (week 4 after discontinuation of infusion).

Data analysis. Statistical analyses were performed using SYSTAT 5.03 (SYSTAT, Evanston, IL). The following variables were included in the analyses: age, to compare 4- and 22-month-old rats; drug, to compare rats receiving vehicle or NGF; groups, to compare each group with the others, and Period, to compare preoperative performance with postoperative performance or to compare performance during different postoperative periods. A period was defined as a block of two (for sensorimotor measures) or three (for DNMTP) test days. A total of five periods were analyzed: PRE, POST1, POST2, POST3, and POST4, as illustrated in Figure 2. Repeated-measures analyses also included the variables days, trials, and sessions (see below).

For preoperative analyses, repeated-measures ANOVAs were conducted on the 4- and 22-month-old age group means for straight swim $($ Age $\times$ Trial), DNMTP choice accuracy (Age $\times$ Session), swim times in the information swim, correct-choice swim, and incorrect-choice swim of DNMTP $($ Age $\times$ Session), and body weight $($ Age $\times$ Day). A $t$ test was conducted on the mean swim time during session 10 for each of the three swim time measures to examine the effect of age on swim time at the end of preoperative testing. $t$ tests were also used to measure age differences in each of the sensorimotor measures. For postoperative analyses, preoperative performance was compared with performance in each of the four postoperative test periods (POST1-POST4). First, an omnibus ANOVA was performed including all four treatment groups and all five test periods. Second, because effects within a particular age group may be overshadowed in the omnibus ANOVA, two focused ANOVAs were conducted (Period $\times$ Drug) followed by planned contrasts when appropriate. Third, separate one-way ANOVAs with planned contrasts were performed for each of the treatment groups separately to compare vehicle or NGF effects in different periods. This series of analyses was conduced for choice accuracy, swim times (for all three types of swims), and sensorimotor scores. For body weight, focused and one-way ANO- 


\begin{tabular}{|l|l|l|l|l|l|l|l|l|l|l|l|l|l|l|}
\hline Task & $\begin{array}{l}\text { PRE } \\
\text { DNMTP }\end{array}$ & $\begin{array}{l}\text { PRE } \\
\text { SM }\end{array}$ & $\begin{array}{l}\text { Surgery 1, } \\
\text { Recovery }\end{array}$ & $\begin{array}{l}\text { POST1 } \\
\text { DNMTP }\end{array}$ & $\begin{array}{l}\text { POST1 } \\
\text { SM }\end{array}$ & $\begin{array}{l}\text { Surgery 2, } \\
\text { Recovery }\end{array}$ & $\begin{array}{l}\text { POST2 } \\
\text { DNMTP }\end{array}$ & $\begin{array}{l}\text { POST2 } \\
\text { SM }\end{array}$ & Rest & $\begin{array}{l}\text { POST3 } \\
\text { DNMTP }\end{array}$ & $\begin{array}{l}\text { POST3 } \\
\text { SM }\end{array}$ & $\begin{array}{l}\text { POST4 } \\
\text { RNMTP }\end{array}$ & $\begin{array}{l}\text { POST4 } \\
\text { SM }\end{array}$ \\
\hline $\begin{array}{l}\text { \# of } \\
\text { Sessions }\end{array}$ & 10 & 2 & 1 week & 3 & 2 & 1 week & 3 & 2 & 1 week & 3 & 2 & 1 week & 3 & 2 \\
\hline $\begin{array}{l}\text { Treatment } \\
\text { week }\end{array}$ & week 0 & week 1 & week 2 & week 3 & week 4 & week 5 & week 6 & week 7 & week 8 \\
\hline
\end{tabular}

Figure 2. Schedule for behavioral testing and surgery. Rest, Period in which no surgical or behavioral procedures occurred; SM, sensorimotor; Surgery 1, pump implantation; Surgery 2, pump replacement. Arrows indicate the beginning and end of NGF or vehicle infusion.

VAs with contrasts were performed for the mean body weight per block of $5 \mathrm{~d}$.

As described above, assignments to treatment groups were made so that the mean choice accuracy during sessions 8-10 was similar between vehicle and NGF groups at a particular age. However, because not all rats tested preoperatively were included in the final data analyses (see Results), the resulting mean preoperative choice accuracy of the vehicle and NGF groups within an age group was not equal. Because of these baseline (PRE) choice accuracy differences between treatment groups at each age, difference scores were obtained by subtracting values for preoperative performance from those in each postoperative period to compare (withinsubjects) choice accuracy during the postoperative periods with each rats' own preoperative performance. ANOVAs were performed on these difference scores to compare choice accuracy between groups.

\section{RESULTS}

\section{Subjects}

The number of rats included in the data analyses were as follows: $4 \mathrm{moVEH}=6,4 \mathrm{moNGF}=6,22 \mathrm{moVEH}=7,22 \mathrm{moNGF}=6$. In all animals included in the data analyses, a cannula track was seen traversing the sensorimotor cortex and ending in the cistern of the anterior lateral ventricle, close to the foramen of Monro. This placement, as explained previously (Koliatsos et al., 1991a), ensures bilateral perfusion of the ventricular system with the trophic factor. The central reservoir of the osmotic pump was fully collapsed in all rats, an indication that the entire amount of drug was delivered (Koliatsos et al., 1994). The efficacy of NGF in this paradigm has been addressed previously (Koliatsos et al., 1994). A total of seven rats were not included in the analyses for a variety of reasons, including the presence of pituitary or soft tissue tumors, unsuccessful infusion, insufficient swimming ability, or death before the completion of the experiment. All 22-month-old rats lost weight during the experiment, and several were given nutritional supplementation consisting of ground rat chow, 0.5$3.0 \mathrm{ml}$ Nutri-Cal dietary supplement (Evsco Pharmaceuticals, Buena, NJ), and/or subcutaneous saline.

\section{Preoperative testing}

\section{Straight swim}

The swim times of the 22-month-old group ranged from $18 \pm 3.96$ in trial 1 to $6.46 \pm 1.26$ in trial 10 , and the times of the 4-monthold group ranged from $12.75 \pm 1.96$ to $5.42 \pm 0.57$. Because the mean swim times of the aged group remained $>10 \mathrm{sec}$ until trial 7 , whereas the mean swim times of the young group remained $<10 \mathrm{sec}$ from trial 2 on, the main effect of age was significant $\left(F_{(1,23)}=7.884, p<0.01\right)$. The swim time of both groups improved during the session (Trial effect, $F_{(9,207)}=5.45, p<0.01$ ), so that by the end of the straight swim session, swim time was not different between the two age groups $(p>0.05)$.

\section{DNMTP choice accuracy}

The choice accuracy of 22-month-old group was significantly lower than that of the 4-month-old group during preoperative training (Fig. 3; Age effect, $F_{(1,23)}=7.74, p<0.05$ ). The mean choice accuracy during session 1 was $37.01 \pm 3.71$ and $48.72 \pm$ 3.89 for the 4- and 22-month-old groups, respectively. The choice accuracy of both age groups improved throughout testing $\left(F_{(9,207)}\right.$ $=14.84, p<0.01)$, but the rate of improvement was different between the groups (Age $\times$ Session, $\left.F_{(9,207)}=3.3, p<0.01\right)$. By the end of testing, mean choice accuracy during sessions 8-10 was $84.58 \pm 3.86$ and $65.26 \pm 4.08$ for the 4 - and 22 -month-old groups, respectively.

\section{DNMTP swim time}

The 22-month-old group showed more prolonged swim times than the 4-month-old group during preoperative training in the information swim $\left(F_{(1,23)}=12.27, p<0.01\right)$, and correct-choice swim $\left(F_{(1,23)}=4.98, p<0.05\right)$, but not in the incorrect-choice swim. Information swim times varied from $24.95 \pm 2.84$ (session 1) to $6.52 \pm 0.69$ (session 10) in the 4-month-old group and from $40.16 \pm 2.99$ (session 1) to $10.2 \pm 1.45$ (session 10) in the 22-month-old group, and correct-choice swim times ranged from $25.92 \pm 5.84$ to $6.78 \pm 1.23$ and $40.37 \pm 3.01$ to $7.44 \pm 1.03$ in the respective age groups, whereas incorrect-choice swim time ranges were more similar between the age groups (41.04 \pm 3.11 to $14.5 \pm$ 1.62 for young and $51.42 \pm 2.29$ to $18.06 \pm 2.27$ for aged). The swim times of both age groups improved throughout testing in all three types of swims (information swim, $F_{(9,207)}=47.7, p<0.01$; correct-choice swim, $F_{(9,207)}=26.0, p<0.01$; incorrect-choice swim, $\left.F_{(9,90)}=9.55, p<0.01\right)$, but the rate of improvement was different between the two age groups in the information and correct-choice swims $\left(F \mathrm{~s}_{(9,207)}=2.74\right.$ and 2.23 , respectively, $p \mathrm{~s}<$

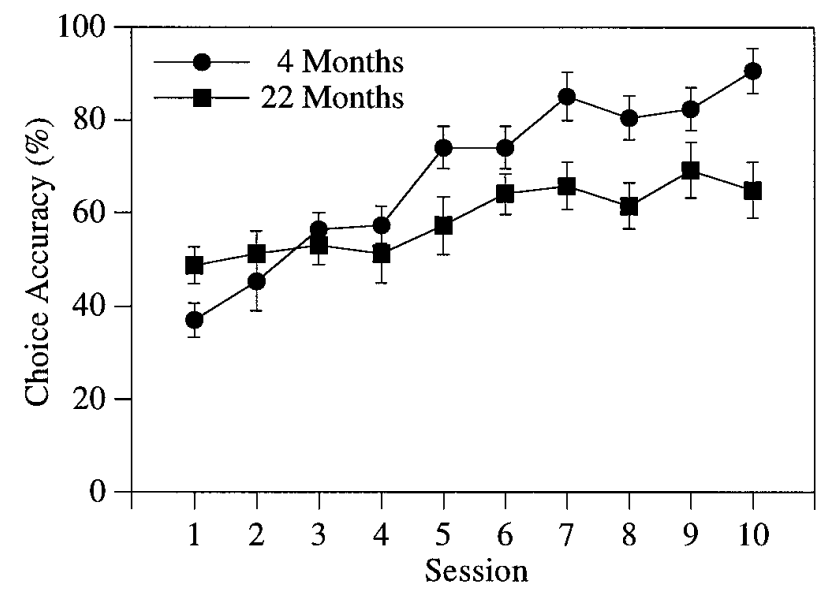

Figure 3. Preoperative choice accuracy for the DNMTP task. The choice accuracy of the 22-month-old group was significantly lower than that of the 4-month-old group during sessions 5, 7, 8, and 10. Each point represents the group mean \pm SEM. 


\begin{tabular}{lcc}
\hline Table 1. Preoperative sensorimotor task raw values & \\
& $\begin{array}{l}\text { 4-Month-old } \\
\text { group }\end{array}$ & $\begin{array}{l}\text { 22-Month-old } \\
\text { group }\end{array}$ \\
Task & $4.9 \pm 0.7$ & $12.4 \pm 1.2^{*}$ \\
\hline Turning in an alley & $50.9 \pm 10.4$ & $98.7 \pm 7.9^{*}$ \\
Escape from $6 \mathrm{~cm}$ bridge & $120.0 \pm 0$ & $77.2 \pm 10.4^{*}$ \\
Fall from $6 \mathrm{~cm}$ bridge & $65.5 \pm 8.5$ & $115.5 \pm 4.2^{*}$ \\
Escape from $2 \mathrm{~cm}$ bridge & $107.3 \pm 5.8$ & $27.4 \pm 8.3^{*}$ \\
Fall from $2 \mathrm{~cm}$ bridge & $111.7 \pm 8.3$ & $120.0 \pm 0$ \\
Escape from round bridge & $28.6 \pm 9.5$ & $2.9 \pm 0.5^{*}$ \\
Fall from round bridge & $22.4 \pm 7.2$ & $4.2 \pm 0.7^{*}$ \\
Fall from wire & $1520.8 \pm 131.8$ & $303.4 \pm 65.2^{*}$ \\
Fall from inclined screen &
\end{tabular}

All values are mean \pm SEM. ${ }^{*} p<0.05$ relative to the 4-month-old group.

0.01). However, by the end of preoperative testing, only swim time in the information swim remained significantly different between the two groups (session 10, $t(23)=4.99, p<0.05$ ), but swim time was not different in the correct-choice and incorrect-choice swims at the end of preoperative testing.

\section{Sensorimotor}

Time to complete each sensorimotor task varied widely among the tasks. However, in all measures but one, the 22-month-old group performed worse than the 4-month-old group (Table 1). To compare different sensorimotor tasks, mean $Z$ scores were calculated for each of the nine measures. Positive $Z$ scores indicated aboveaverage performance, and negative $Z$ scores indicated belowaverage performance. The nine $Z$ scores were also averaged to yield one combined $Z$ score for each test period representing overall sensorimotor ability. The 22-month-old group was impaired relative to the 4-month-old group in all sensorimotor measures $(t \mathrm{~s}(23)=6.86-71.94, p s<0.05)$ except for the escapefrom-the-round-bridge measure. Accordingly, the combined $Z$ score was also significantly different between the age groups $(t(23)$ $=75.9, p<0.01)$.

\section{Body weight}

During preoperative days 1-15, the body weights of the two 4-month-old groups did not significantly differ; $4 \mathrm{moVEH}$ weights ranged from $314 \pm 13.2$ (day 1) to $323 \pm 10.27$ (day 15), and 4 moNGF weights ranged from $299.33 \pm 14.52$ to $308 \pm 12.93$. Both 4-month-old groups gained weight similarly throughout the preoperative testing (Day effect, $F_{(14,140)}=6.17, p<0.01$; Group $\times$ Day effect, $p>0.05)$. The preoperative body weights of the two 22-month-old groups also did not significantly differ $(443.71 \pm 9.98$ to $408.86 \pm 9.4$ for $22 \mathrm{moVEH}$, and $435.6 \pm 11.32$ to $405.17 \pm 9.4$ for $22 \mathrm{moNGF}$ ), and both groups lost weight similarly throughout testing (Day effect, $F_{(14,126)}=29.55, p<$ 0.01 ; Group $\times$ Day effect, $\left.F_{(14,126)}=0.44, p>0.05\right)$.

\section{Postoperative testing}

\section{DNMTP choice accuracy}

The omnibus ANOVA revealed a significant effect of groups $\left(F_{(3,21)}=10.87, p<0.01\right)$, primarily attributable to a significant effect of age. The choice accuracy of the $22 \mathrm{moVEH}$ group was significantly lower than that of both 4-month-old groups during all test periods $(p s<0.05)$. Choice accuracy varied depending on the period tested, as indicated by a significant Period effect $\left(F_{(4,84)}=\right.$ $3.98, p<0.05)$. The choice accuracy of both 4-month-old groups was not significantly altered in any period (Period effects, $p \mathrm{~s}>$ $0.05)$. Choice accuracy of the 4 moNGF group was slightly in-
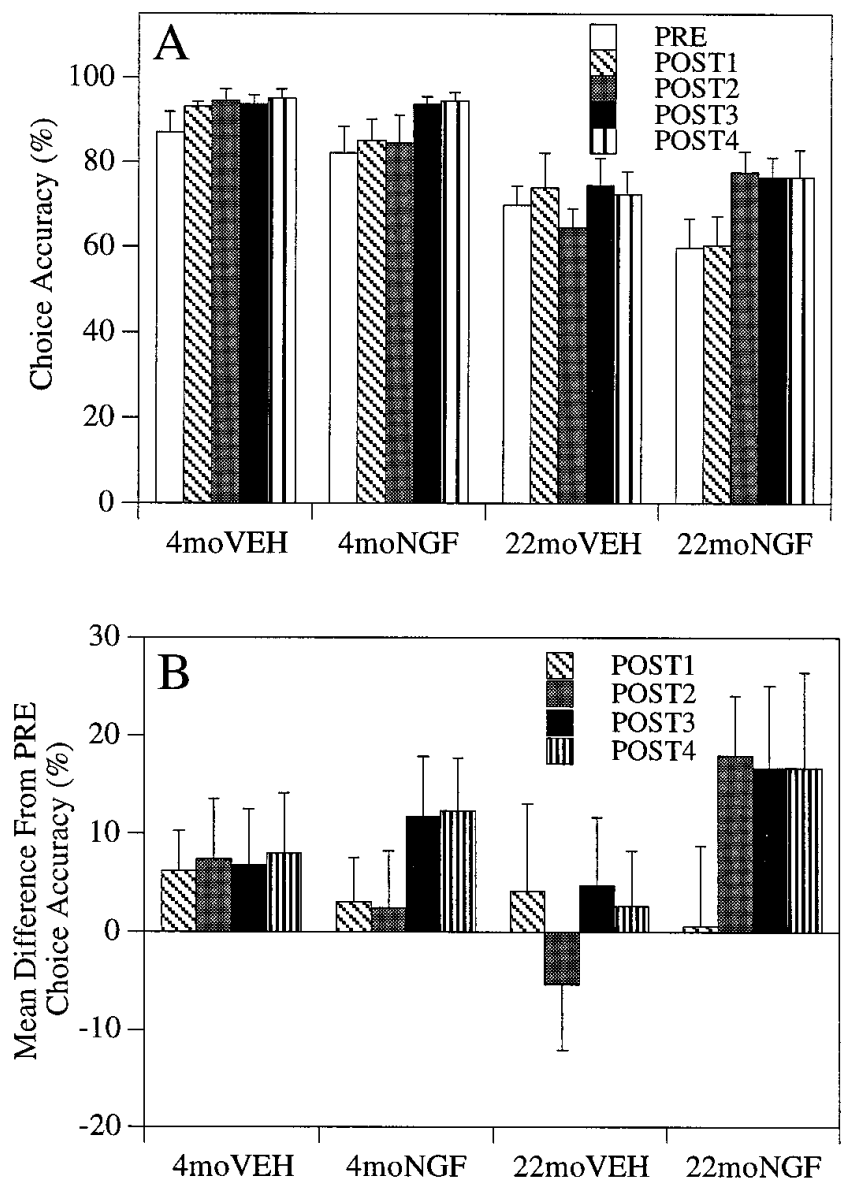

Figure 4. A, Pre- and postoperative choice accuracy for the DNMTP task. Each bar represents the mean \pm SEM choice accuracy for three sessions as follows: PRE, sessions 8-10; POST1, sessions 11-13; POST2, sessions 14-16; POST3, sessions 17-19; POST4, sessions 20-22. The choice accuracy of the $22 \mathrm{moNGF}$ group was significantly increased during POST2 relative to PRE, and this increase was maintained during POST3 and POST4. $B$, Choice accuracy difference scores for each POST period. The difference between POST2-POST4 and PRE in the 22moNGF group was significantly larger than that of the $22 \mathrm{moVEH}$ group.

creased during POST3 and POST4 relative to their own PRE (Fig. $4 A$ ), but this increase was not significant. A focused ANOVA including both 4-month-old groups performed on the difference scores revealed no significant effects of drug or period, confirming the lack of NGF effect on choice accuracy in the 4moNGF group.

A significant effect of NGF was observed in the 22-month-old rats. The choice accuracy of the $22 \mathrm{moNGF}$ group was increased from $59.88 \pm 6.86$ in PRE to $77.8 \pm 4.87,76.56 \pm 4.65$, and $76.56 \pm 6.39$ in POST2, POST3, and POST4, respectively (Fig. $4 A$ ). In the $22 \mathrm{moNGF}$ group, the one-way ANOVA revealed significant differences among periods of testing $\left(F_{(4,20)}=2.97\right.$, $p<0.05)$. The choice accuracy of 22 moNGF rats was significantly improved after 4 weeks of infusion (i.e., POST2 compared with PRE level, $p<0.05)$ and remained elevated after discontinuation of the treatment during the following 4 weeks (both POST3 and POST4 not different from POST2, $p>0.05$; Fig. 4A). Choice accuracy did not differ between PRE and POST1, demonstrating that NGF did not have a significant effect on choice accuracy after 2 weeks of infusion. In contrast, choice accuracy in the $22 \mathrm{moVEH}$ group was not significantly improved relative to PRE in any postoperative period $(p>0.05)$. The focused ANOVA including 
both 22-month-old groups performed on the difference scores (Fig. $4 B)$ revealed a significant Drug $\times$ Period interaction $\left(F_{(3,33)}\right.$ $=2.8, p=0.05)$, suggesting that NGF had significantly more of an effect on choice accuracy during POST2-POST4 than did the vehicle.

\section{DNMTP swim time}

Aging significantly affected the information swim (omnibus ANOVA, $\left.F_{(1,21)}=23.0, p<0.05\right)$, but not the correct-choice and incorrect-choice swims. In 4-month-old rats, neither vehicle nor NGF infusion significantly affected any of the swim time measures during any postoperative period; in the information swim, PRE and POST4 swim times ranged from $6.12 \pm 0.59$ to $6.92 \pm 1.1$ in $4 \mathrm{moVEH}$ and from $6.5 \pm 1.13$ to $6.36 \pm 0.57$ in $4 \mathrm{moNGF}$; in the correct-choice swim, times ranged from $5.28 \pm 0.88$ to $7.7 \pm 1.86$ in $4 \mathrm{moVEH}$ and from $6.93 \pm 1.22$ to 5.48 to 0.65 in $4 \mathrm{moNGF}$; in the incorrect-choice swim, times ranged from $11.73 \pm 0.75$ to $17.25 \pm 1.15$ and from $14.96 \pm 1.88$ to $13.8 \pm 2.15$ in 4 moNGF. Vehicle infusion did not affect 22-month-old rats during any postoperative period (times ranged from $6.41 \pm 0.91$ to $20.23 \pm$ 2.14), but NGF infusion in 22-month-old rats increased swim time in all three swim time measures during POST1 (16.82 \pm 2.43 , $11.72 \pm 2.11$, and $23.98 \pm 3.92$ for information, correct-choice, and incorrect-choice swims, respectively) relative to their own PRE values $(10.37 \pm 0.81,6.55 \pm 0.82$, and 18.52 \pm 1.91 , respectively) or to the PRE value of the $22 \mathrm{moVEH}$ group ( $p \mathrm{~s}<0.05$ ). The increased POST1 swim times likely contributed to the significant Period $\times$ Age, Period $\times$ Drug, and Period $\times$ Age $\times$ Drug effects observed in the omnibus ANOVAs for the information swim and incorrect-choice swim $(p s<0.05)$. The NGF-induced increases in swim time were transient, as demonstrated by a return to preoperative levels during POST2-POST4.

\section{Sensorimotor}

Aging significantly affected overall sensorimotor skills (omnibus ANOVA for combined $Z$ score, $\left.F_{(1,21)}=112.7, p<0.01\right)$. Neither vehicle nor NGF significantly affected sensorimotor measures in 4-month-old rats either during infusion or after the termination of infusion. Likewise, sensorimotor performance was not significantly altered during any period by vehicle infusion in the 22month-old rats. However, overall sensorimotor performance was significantly affected by NGF in the 22-month-old rats (Period effect, $\left.F_{(4,20)}=3.49, p<0.05\right)$. As illustrated in Figure 5, NGF significantly improved overall sensorimotor performance in the 22-month-old group during POST3 and POST4 relative to PRE $(p s<0.05)$. This effect was primarily attributable to improved performance on the $6 \mathrm{~cm}$ bridge (Period effect in time to escape, $\left.F_{(4,20)}=4.2, p<0.05\right)$ during POST3 and POST4 $(p s<0.05)$. Mean time to escape from the $6 \mathrm{~cm}$ bridge was $113.92 \pm 6.08$ preoperatively and decreased to $59.75 \pm 15.94$ and $72.5 \pm 18.93$ in POST3 and POST4, respectively.

\section{Body weight}

The one-way ANOVA performed on blocks of $5 \mathrm{~d}$ revealed significant differences between the two 4-month-old groups during postoperative testing (Drug effect, $F_{(1,10)}=5.7, p<0.05$; Period effect, $F_{(4,40)}=34.7, p<0.01$; Period $\times$ Drug effect, $F_{(4,40)}=3.4$, $p<0.05)$. The body weight of the $4 \mathrm{moVEH}$ group increased significantly during each period relative to the previous period $(p s<0.05)$ and was significantly higher than that of the 4moNGF group during POST2, POST3, and POST4 ( $p$ s $<0.05$, Fig. 6). Although the body weight of the 4 moNGF group remained lower

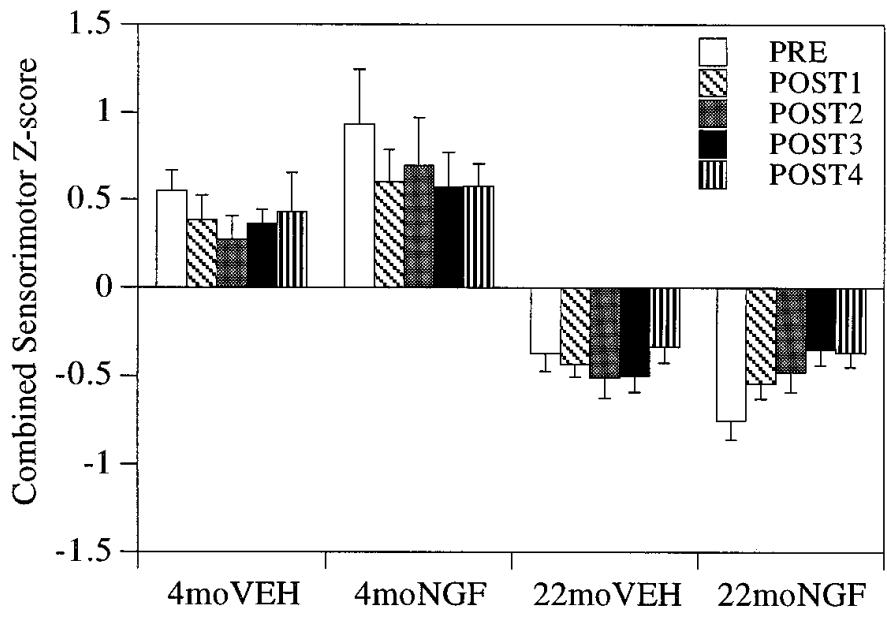

Figure 5. Pre- and postoperative sensorimotor $Z$ scores. Positive $Z$ scores indicate above-average performance, and negative $Z$ scores indicate below-average performance. NGF improved overall sensorimotor skills in 22-month-old rats only after discontinuation of infusion (POST3 and POST4). Each bar represents the mean combined $Z$ score $\pm \mathrm{SEM}$ for each treatment group during one test period ( 2 sessions/period).

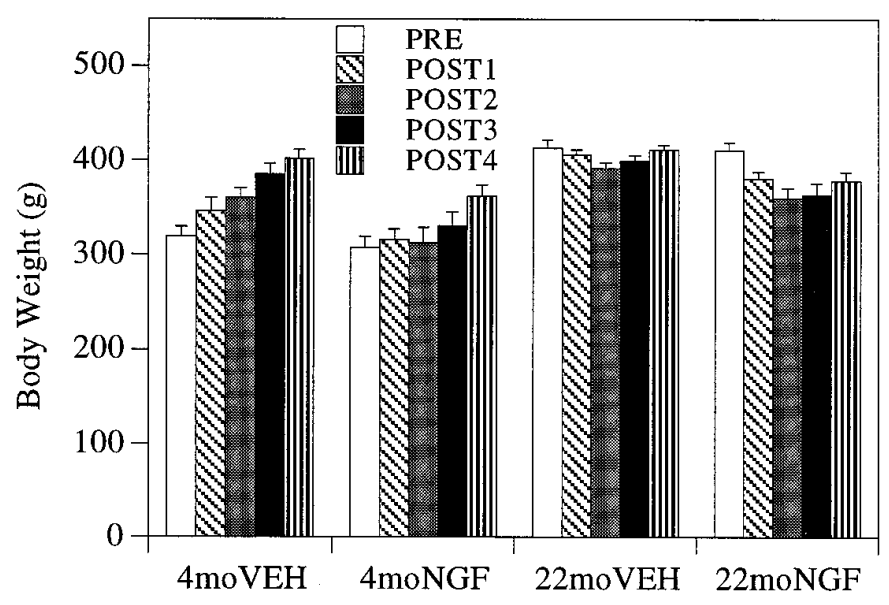

Figure 6. Pre- and postoperative body weight. NGF infusion decreased body weight in 22-month-old rats and inhibited weight gain in 4-month-old rats both during infusion and after the discontinuation of infusion. All groups gained weight during POST3 and POST4, after discontinuation of infusion. Each bar represents the treatment group mean $\pm \mathrm{SEM}$ for PRE (days 11-15), POST1 (days 16-20), POST2 (days 21-25), POST3, (days 26-30), or POST4 (days 31-35).

than that of the 4moVEH group throughout postoperative testing, 4 moNGF body weight did increase after discontinuation of NGF administration, as suggested by a significant difference between POST4 and PRE $(p<0.05)$.

The body weight of the 22 moNGF group was significantly lower than that of the $22 \mathrm{moVEH}$ group throughout all four POST periods (Fig. 6; Drug effect, $F_{(1,11)}=10.93, p<0.01$ and Period effect, $\left.F_{(4,44)}=9.77, p<0.01\right)$. Both groups lost weight during POST1 and POST2 $(p s<0.05)$ but increased body weight during POST3 and POST4 (after discontinuation of NGF infusion; Fig. 6). In both 22-month-old groups, the difference between PRE and POST4 body weights was not significant, suggesting an increase toward preoperative levels. However, the body weights of the $22 \mathrm{moNGF}$ group remained lower than that of the $22 \mathrm{moVEH}$ group during POST3 and POST4 $(p s<0.05)$. 


\section{DISCUSSION}

\section{NGF effects on spatial recent memory}

The present study demonstrates for the first time that the NGFinduced improvement of spatial recent memory in 22-month-old rats can be maintained for up to 4 weeks after discontinuation of NGF infusion and suggests a prolonged beneficial effect of NGF on memory in aged rats. The fact that NGF infusion did not significantly affect the swim time of aged rats during POST2POST4 suggests that the improved choice accuracy during these three periods was not the result of improved swimming ability but of improved memory. In addition, improvements in choice accuracy were not affected by age-related or NGF-induced changes in body weight, suggesting that NGF did not simply influence the overall health of the aged rats. The persistence of the NGFinduced memory improvement is not likely to be caused by the effects of repeated testing, as illustrated by the fact that aged rats receiving vehicle did not benefit from repeated testing. This conclusion is supported by the results of another study of aged rats, in which the improved T-maze choice accuracy and altered hippocampal electrophysiology observed after acute intraseptal oxotremorine infusion returned to preinfusion levels within 90 min (Markowska et al., 1995). Thus, if chronic NGF infusion did not result in persistent neuronal alterations, then improved DNMTP choice accuracy and stimulated cholinergic function should decrease to preinfusion levels after the discontinuation of NGF treatment. Because both choice accuracy (the present study) and cholinergic function (Vantini et al., 1990) remain improved after discontinuation of NGF infusion, it is likely that NGF exerts a prolonged effect in the aged brain. The likelihood that prolonged changes in mnemonic function parallel persistent changes in the biology of cholinergic neurons suggests that continuous treatment with NGF is not necessary to maintain the beneficial effects of NGF infusion, and this finding provides valuable information regarding the utility of NGF in intermittent treatment regimens for age-associated memory disorders.

Consistent with previous reports in aged rats (Markowska et al., 1994, 1996), spatial recent memory was significantly improved during the 4th week of continuous NGF infusion. However, in young rats, NGF did not significantly affect spatial recent memory after 2-4 weeks of infusion. It is unlikely that the lack of improvement was attributable to a ceiling effect during preoperative testing. Previously, we have shown that the choice accuracy of young rats with lower preoperative choice accuracy than those in this study were also not improved (Markowska et al., 1996). Similarly, inspection of individual data in this study showed that even those young rats with the lowest choice accuracy were not improved by NGF. In fact, choice accuracy in the 4moNGF group was slightly, but not significantly, decreased during NGF infusion, a result consistent with a previous study using the DNMTP procedure (Markowska et al., 1996). In a T-maze delayed-alternation task, the choice accuracy of 4-month-old rats receiving NGF was significantly decreased relative to 4-month-old controls, as well as to their own preinfusion performance (Markowska et al., 1994). As stated previously (Markowska et al., 1996), this difference between results obtained in the T-maze and water maze may be related to differences in motivation used in the two experiments, that is, water restriction in the T-maze task as opposed to escape from water in the water maze task. Given the suppression of weight gain induced by NGF, choice accuracy in the T-maze was likely affected by a decreased motivation to perform the task. Alternatively, the fact that choice accuracy in both studies using the DNMTP procedure was slightly (but nonsignificantly) decreased during NGF infusion suggests that NGF impairs memory in young rats. However, this effect may be exacerbated by food deprivation rather than by decreased motivation to perform the task.

\section{NGF effects on sensorimotor skills}

Overall sensorimotor skills were improved in aged rats only after the discontinuation of NGF infusion. The NGF-related improvement was observed both 2 and 4 weeks after discontinuation of infusion. This improvement was reflected most in one sensorimotor measure, time to escape from the $6 \mathrm{~cm}$ bridge, which measures balance, coordination, and upper body strength. Although it is unclear why this task was the most robustly improved in relationship to NGF infusion, it is possible that it reflects an NGFsensitive aspect of sensorimotor skills not measured by the other tasks. Alternatively, the lower level of difficulty of this measure may indicate that NGF is more useful in improving performance on less challenging motor tasks.

Consistent with the previous report by Markowska et al. (1994), no significant sensorimotor improvement was observed during NGF infusion in either 4- or 22-month-old rats. These data contradict an earlier study in which a significant increase in the time to fall from the inclined screen was observed in aged rats during the 3rd week of NGF infusion (Williams et al., 1993). The inconsistency between the results of this study and that of Williams et al. (1993) may be related to the different types of NGF molecules used (recombinant human NGF in the present study vs mouse NGF in Williams et al., 1993), although these molecules have been reported to have similar effects on basal forebrain cholinergic neurons (Koliatsos et al., 1991a,b; Tuszynski et al., 1991).

The overall sensorimotor improvements observed in the present study after discontinuation of NGF treatment are likely attributable to effects of NGF on the striatum. NGF infused into the lateral ventricles can diffuse into the striatum (Yan et al., 1994), where cholinergic interneurons express trk A receptors (Holtzman et al., 1992). NGF infused into the lateral ventricles of aged rats for 2 weeks causes changes in the structure and transmitter metabolism of striatal cholinergic neurons (Fischer et al., 1987; Williams and Rylett, 1990; Rylett et al., 1993), indicating that intraventricular NGF can significantly affect the striatal cholinergic system. Although it is unclear why these changes in striatal cholinergic function occur sooner than the improvements in sensorimotor skills observed in the present study, this pattern is consistent with that in the septohippocampal cholinergic system in which NGF-induced stimulation of cholinergic function precedes improvements in spatial memory (Fischer et al., 1987, 1991; Markowska et al., 1994).

\section{NGF effects on body weight}

NGF significantly inhibited weight gain in 4-month-old rats, a result consistent with previous studies (Williams, 1991; Lapchak and Hefti, 1992; Lapchak and Araujo, 1994; Markowska et al., 1996). It is clear that the lower mean body weight of the 4moNGF group was not the result of differential exercise between the $4 \mathrm{moVEH}$ and $4 \mathrm{moNGF}$ rats, because all 4-month-old rats spent a similar amount of time swimming in the water. For example, the two 4-month-old groups had similar swim times and showed similar choice accuracy. NGF-induced inhibition of weight gain appears to be the result of appetite suppression, rather than of metabolic alterations in the periphery (Pelleymounter et al., 1995) 
and may result from NGF influences on the basal forebrain or other brain structures adjacent to the ventricles. In rats, the septum is involved in the regulation of food and water intake via its projections to the hypothalamus and, in fact, electrical stimulation of the septum results in weight loss (Oliveira et al., 1990). Therefore, by stimulating the septal cholinergic input to the hypothalamus, NGF may result in appetite suppression. Alternatively, NGF may directly affect the hypothalamus via diffusion from the third ventricle. In young rats, NGF-induced inhibition of weight gain after intraventricular administration of the factor correlates with decreases in hypothalamic cholecystokinin levels (Lapchak and Araujo, 1994), although it is not entirely clear whether these peptide changes represent a direct or an indirect hypothalamic effect of NGF.

NGF also significantly decreased body weight in 22-month-old rats both during infusion and after discontinuation of treatment. The mechanism of this weight loss is likely similar to that in young rats. Both $22 \mathrm{moVEH}$ and $22 \mathrm{moNGF}$ groups gained weight after discontinuation of infusion, a pattern that suggests an adverse effect of the infusion per se. It is unlikely that the neurological intervention itself contributed to the weight loss, because young rats receiving vehicle gained weight throughout the experiment, and aged rats gained weight during the POST3 and POST4 periods in which the pump was empty. One possibility is that aged rats take longer to fully recover from surgery than young rats, and thus, may eat less during the 2 weeks immediately after surgery. No surgical procedures were performed before the POST3 and POST4 periods, possibly allowing the aged rats to fully recover and resume normal food intake.

\section{Conclusion}

The results of the present experiment are the first demonstration of the persistence of NGF-induced improvements in spatial recent memory in aged rats. This finding extends previous observations of the robust effects of NGF on spatial recent memory (Markowska et al., 1994, 1996) by establishing the long-term effects of NGF treatment. These effects are likely mediated via persisting structural changes in the cell bodies, axons, and terminals of basal forebrain cholinergic neurons (Fischer et al., 1987), although effects on postsynaptic cortical/hippocampal neurons cannot be ruled out (Mervis et al., 1991). Consequently, our data suggest that NGF can be used intermittently for the treatment of age-associated memory dysfunction as it occurs in AD and associated disorders.

\section{REFERENCES}

Bartus RT, Dean RL, Pontecorvo MJ, Flicker C (1985) The cholinergic hypothesis: a historical overview, current perspectives, and future directions. Ann NY Acad Sci 444:332-358.

Bondi MW, Salmon DP, Butters N (1994) Neuropsychological features of memory disorders in Alzheimer's disease. In: Alzheimer's disease (Terry RD, Katzman R, Bick KL, eds). New York: Raven.

Craik FIM (1977) Age differences in human memory. In: Handbook of the psychology of aging (Birren JE, Schaie KW, eds), pp 384-420. New York: Van Nostrand Reinhold.

Damasio AR, Eslinger PJ, Damasio H, Van Hoesen GW, Cornell S (1985) Multimodal amnesiac syndrome following bilateral temporal and basal forebrain damage. Arch Neurol 42:252-259.

deToledo-Morrell L, Morrell F, Fleming S (1984) Age related deficits in spatial memory and hippocampal plasticity. Behav Neurosci 98:902-907.

Drachman DA, Leavitt J (1974) Human memory and the cholinergic system. A relationship to aging? Arch Neurol 30:113-121.

Fischer W, Wictorin K, Björklund A, Williams LR, Varos S, Gage FH (1987) Amelioration of cholinergic neuron atrophy and spatial memory impairment in aged rats by nerve growth factor. Nature 329:65-68.
Fischer W, Björklund A, Chen K, Gage FH (1991) NGF improves spatial memory in aged rodents as a function of age. J Neurosci 11:1889-1906.

Fischer W, Sirevaag A, Wiegand SJ, Lindsay RM, Björklund A (1994) Reversal of spatial memory impairments in aged rats by nerve growth factor and neurotrophins 3 and $4 / 5$ but not by brain-derived neurotrophic factor. Proc Natl Acad Sci USA 91:8607-8611.

Francis PT, Cross AJ, Bowen DM (1994) Neurotransmitters and neuropeptides. In: Alzheimer's disease (Terry RD, Katzman R, Bick KL, eds). New York: Raven.

Frotscher M, Leranth C (1985) Cholinergic innervation of the rat hippocampus as revealed by choline acetyltransferase immunocytochemistry: a combined light and electron microscopic study. J Comp Neurol 239:237-246.

Hefti F (1986) Nerve growth factor promotes survival of septal cholinergic neurons after fimbrial transections. J Neurosci 6:2155-2162.

Holtzman DM, Li Y, Parada LF, Kinsman S, Chen C-K, Valletta JS, Zhou J, Long JB, Mobley WC (1992) p140 ${ }^{\text {trk }}$ mRNA marks NGF-responsive forebrain neurons: evidence that trk gene expression is induced by NGF. Neuron 9:465-478.

Ingram DK, Joseph JA, Spangler EL, Roberts D, Hengemihle J, Fanelli RJ (1994) Chronic nimodipine treatment in aged rats: analysis of motor and cognitive effects and muscarinic-induced striatal dopamine release. Neurobiol Aging 15:55-61.

Koliatsos VE, Martin LJ, Price DL (1990a) Efferent organization of the mammalian basal forebrain. In: Brain cholinergic systems (Steriade M, Biesold D, eds), pp 120-152. New York: Oxford UP.

Koliatsos VE, Nauta WHJ, Clatterbuck RE, Holtzman DM, Mobley WC, Price DL (1990b) Mouse nerve growth factor prevents degeneration of axotomized basal forebrain cholinergic neurons in the monkey. J Neurosci 10:3801-3813.

Koliatsos VE, Applegate MD, Knüsel B, Junard EO, Burton LE, Mobley WC, Hefti FF, Price DL (1991a) Recombinant human nerve growth factor prevents retrograde degeneration of axotomized basal forebrain cholinergic neurons in the rat. Exp Neurol 112:161-173.

Koliatsos VE, Clatterbuck RE, Nauta WHJ, Knüsel B, Burton LE, Hefti FF, Mobley WC, Price DL (1991b) Recombinant human nerve growth factor prevents degeneration of basal forebrain cholinergic neurons in primates. Ann Neurol 30:831-840.

Koliatsos VE, Price DL, Gouras GK, Cayouette MH, Burton LE, Winslow JW (1994) Highly selective effects of nerve growth factor, brainderived neurotrophic factor, and neurotrophin-3 on intact and injured basal forebrain magnocellular neurons. J Comp Neurol 343:247-262.

Lapchak PA, Araujo DM (1994) NGF suppression of weight gain in adult female rats correlates with decreased hypothalamic cholecystokinin levels. Brain Res 655:12-16.

Lapchak PA, Hefti F (1992) BDNF and NGF treatment in lesioned rats: effects on cholinergic function and weight gain. NeuroReport 3:405-408.

Luine V, Hearns M (1990) Spatial memory deficits in aged rats: contributions of the cholinergic system assessed by ChAT. Brain Res 523:321-324.

Markowska AL, Olton DS, Murray EA, Gaffan D (1989) A comparative analysis of the role of fornix and cingulate cortex in memory: rats. Exp Brain Res 74:187-201.

Markowska AL, Koliatsos VE, Breckler SJ, Price DL, Olton DS (1994) Human nerve growth factor improves spatial memory in aged but not in young rats. J Neurosci 14:4815-4824.

Markowska AL, Olton DS, Givens B (1995) Cholinergic manipulations in the medial septal area: age-related effects on working memory and hippocampal electrophysiology. J Neurosci 15:2063-2073.

Markowska AL, Price D, Koliatsos VE (1996) Selective effects of nerve growth factor on spatial recent memory as assessed by a delayed nonmatching-to-position task in the water maze. J Neurosci 16:3541-3548.

Mervis RF, Pope D, Lewis R, Dvorak RM, Williams LR (1991) Exogenous nerve growth factor reverses age-related structural changes in neocortical neurons in the aging rat. Ann NY Acad Sci 640:95-101.

Mesulam M-M, Mufson EJ, Wainer BH, Levey AI (1983) Central cholinergic pathways in the rat: an overview based on an alternative nomenclature. Neuroscience 10:1185-1201.

Oliveira LA, Gentil CG, Covian MR (1990) Role of the septal area in feeding behavior elicited by electrical stimulation of the lateral hypothalamus. Braz J Med Biol Res 23:49-58.

Olton DS (1977) Spatial memory. Sci Am 6:82-98.

Pelleymounter MA, Cullen MJ, Wellman CL (1995) Characteristics of BDNF-induced weight loss. Exp Neurol 131:229-238. 
Petty BG, Cornblath DR, Adornato BT, Chaudhry V, Flexner C, Wachsman M, Sinicropi D, Burton LE, Peroutka SJ (1994) The effect of systematically administered recombinant human nerve growth factor in healthy human subjects. Ann Neurol 36:244-246.

Rye DB, Wainer BH, Mesulam MM, Mufson EJ, Saper CB (1984) Cortical projections arising from the basal forebrain: a study of cholinergic and noncholinergic components employing combined retrograde tracing and immunohistochemical localization of choline acetyltransferase. Neuroscience 13:627-643.

Rylett RJ, Goddard S, Schmidt BM, Williams LR (1993) Acetylcholine synthesis and release following continuous intracerebral administration of NGF in adult and aged Fischer-344 rats. J Neurosci 13:3956-3963.

Scoville WB, Milner B (1957) Loss of recent memory after bilateral hippocampal lesions. J Neurol Neurosurg Psychiatry 20:11-21.

Squire LR, Zola-Morgan S, Chen KS (1988) Human amnesia and animal models of amnesia: performance of amnesic patients on tests designed for the monkey. Behav Neurosci 102:210-221.

Thal LJ (1994) Clinical trials in Alzheimer's disease. In: Alzheimer's disease (Terry RD, Katzman R, Bick KL, eds). New York: Raven.

Tuszynski MH, U HS, Amaral DG, Gage FH (1990) Nerve growth factor infusion in the primate brain reduces lesion-induced cholinergic neuronal degeneration. J Neurosci 10:3604-3614.

Tuszynski MH, Sang H, Yoshida K, Gage FH (1991) Recombinant human nerve growth factor infusions prevent cholinergic neuronal degeneration in the adult primate brain. Ann Neurol 30:625-636.
Vantini G, Fusco M, Schiavo N, Gradkowska M, Zaremba M, Leon A, Oderfeld-Nowak B (1990) Nerve growth factor induces a dosedependent and long-lasting increase of choline acetyltransferase activity in the septal area and hippocampus of uninjured rats. Acta Neurobiol Exp 50:323-332.

Williams LR (1991) Hypophagia is induced by intracerebroventricular administration of nerve growth factor. Exp Neurol 113:31-37.

Williams LR, Rylett RJ (1990) Exogenous nerve growth factor increases the activity of high-affinity choline uptake and choline acetyltransferase in brain of Fisher-344 male rats. J Neurochem 55:1042-1049.

Williams LR, Varon S, Peterson GM, Wictorin K, Fischer W, Björklund A, Gage FH (1986) Continuous infusion of nerve growth factor prevents basal forebrain neuronal death after fimbria fornix transection. Proc Natl Acad Sci USA 83:9231-9235.

Williams LR, Rylett RJ, Ingram DK, Joseph JA, Moises HC, Tang AH, Mervis RF (1993) Nerve growth factor affects the cholinergic neurochemistry and behavior of aged rats. Prog Brain Res 98:251-256.

Woolf CJ, Ma QP, Allchorne A, Poole S (1996) Peripheral cell types contributing to the hyperalgesic action of nerve growth factor in inflammation. J Neurosci 16:2716-2723.

Yan Q, Matheson C, Sun J, Radeke MJ, Feinstein SC, Miller JA (1994) Distribution of intracerebral ventricularly administered neurotrophins in rat brain and its correlation with trk receptor expression. Exp Neurol 127:23-36. 